\title{
ARTICLE
}

\section{Evaluation of external radiation exposure of workers engaged in loading of radioactive material shipping cask between ship and truck by crane}

\author{
Yoshihiro Hirao* \\ National Maritime Research Institute, 6-38-1 Shinkawa, Mitaka-shi, Tokyo, 181-0004, Japan
}

\begin{abstract}
In the marine transportation of radioactive material shipping casks, a loading/unloading cargo work has been carried out using a large crane between a ship and a truck at the interface of land and sea. At that time there is a radiation exposure situation where a worker should approach a cask for handling, tie-down and dosimetric inspection. For a spent fuel cask whose surface dose rate is relatively high, it is necessary to evaluate a radiological risk for cargo workers as one of the planned exposure situations since there is no valid shielding between cask and worker for a long time. In order to instantly evaluate worker dose under any working environment, it is necessary to prepare a simple method that accurately calculate a dose rate map around a cask of interest. In this study, simple calculation methods developed for a spent fuel cask have been surveyed to determine the best fit parameters for a representative type-B wet cask of Japan NFT14P. Then, worker dose is practically evaluated by using the parameters under working environment of cask loading in Japan. There assumed to be three types of cargo workers; handler, inspector and spotter. It is found that the highest individual dose is evaluated to $1.70 \mu \mathrm{Sv}$ per cask loading for an inspector on a carrier of truck and the annual cumulative dose will be well below the annual public limit of $1 \mathrm{mSv}$. The collective dose per loading is amounted to about 17 man- $\mu S v$ in a total of 19 workers. The occurrence of latent effects can be negligible but the dose values are still higher compared to estimated exposures for escort and off-link population along a road route in U.S. land transportation of spent fuel.
\end{abstract}

Keywords: external radiation exposure; worker dose; spent fuel; shipping cask; crane loading; marine transportation; truck; simple calculation method; radiological risk

\section{Introduction}

Marine transportation has usually been performed for shipping a type-B cask storing spent fuels (SF) or nuclear wastes in Japan. When a transport mode is changed from sea/land to land/sea, a cask is loaded or unloaded from ship/truck to truck/ship at a harbor. Due to concerns about a radiological risk posed to workers working near a SF cask whose surface dose rate is relatively high, an external radiation exposure of workers should be evaluated to manage a planned exposure situation. In the United States, it was pointed out that the collective dose to cargo workers may exceed a few orders of magnitude comparing with that to public on and around a road during land transportation [1]. As for Japan, public does not exist along a marine route and near a harbor. Because of that, a dose to cargo workers may draw more attention than other potential hazards of routine transportation.

Worker dose can be evaluated using a dose rate map around a cask and a working environment such as working time and arrangement. In this paper, two

*Corresponding author. Email: tora@nmri.go.jp subjects are studied. First, for a wet-type SF cask employed in Japan, the best fitting parameters are determined to express a map by a simple calculation method. A simple method is useful for instantly calculating a dose in any position around a cask. It is also required to do as accurately as possible because priority and effect of protection will be studied by comparing with risk values of other situation in transportation. Second, using the fitting parameters, worker dose per loading is practically evaluated under cargo working conditions in Japan. Finally, an annual dose is estimated based on the possible loadings to discuss in terms of a radiological risk.

\section{Simple calculation method for evaluating dose rate map around the Japanese wet-type SF cask}

\subsection{Survey of simple calculation equation for evaluating dose rate map around a SF cask}

We surveyed the past studies about simple calculation methods to determine a fitting equation or parameter for a type-B wet SF cask employed in Japan. Three typical equations of similar purpose have been examined. 
Yamakoshi proposed a general-purpose analytic function with a cask geometry and surface dose rate at a center of cask body (body center), and implemented it in the calculation code SMART $[2,3]$. It is assumed that a flux emitted from the unit area of body surface would be equal along the axis of cask, and a direction angle of the flux against surface normal vector follows the cosine distribution. Sandquist et al. developed the calculation code PATHRAE-T based on an analytic function on the assumption that a cask is regarded as a line source object [4]. It is possible that these two codes can evaluate a dose rate at a position far off from a cask although a range of use is unverified. Weiner et al. simplified the Sandquist equation to conservatively evaluate a radiological risk for public and worker near a cask and implemented it in the transportation risk assessment code RADTRAN4 [5]. This code can evaluate a dose rate only from the body center for a direction that is vertical to surface. It is expressed using a dose rate $1 \mathrm{~m}$ distant from surface ( $1 \mathrm{~m}$ dose rate) of the body center and a representative dimension of cask.

Calculation results for the above codes are compared by normalizing them in two ways. Figure 1 illustrates four evaluation directions (dir 1 to 4) along which attenuation curves are drawn on a graph. Dir 1, 2 and 4 represent directions for which an inspector has measured a dose rate during a radiation inspection.

One is to normalize attenuation curves for dir 2 and 3 by that of dir 1 for each of the equations. Figure 2 shows the normalized curves of both the PATHRAE-T and the SMART. Note that the RADTRAN4 is omitted because it can be calculated only for dir 1. Conventionally, a simple equation has been developed based on a curve for dir 1 and then extended to curves for other directions. This helps to examine relative differences at a particular distance and find a reference distance among curves.

Another is to determine a reference distance common to curves and then normalize each curve by a dose rate at the distance of the curve. In this study, $1 \mathrm{~m}$ is used as a reference distance for reason as explained later. Figure 3 shows attenuation ratio curves of equations for each direction. This helps to know an attenuation feature by equation and then find a fit one in comparison to an attenuation ratio of a cask of interest.

\subsection{Monte Carlo calculation of dose rate map around the Japanese wet-type SF cask NFT14P}

A cask of interest in this study is the NFT14P type cask, a representative of the wet-type SF casks employed in Japan. It stores 14 PWR fuel assemblies at most and gives highest surface dose rate among them. An inner cavity of cask is filled with pool water and the total weight is over 100 tons. A cask is loaded or unloaded one by one between ship and truck using a large crane at a harbor of both a reprocessing and a nuclear power plant. For the NFT14P, Figures 2 and 4 show the normalized curves by dir 1 and the normalized ratio curves by $1 \mathrm{~m}$ dose rate, respectively.

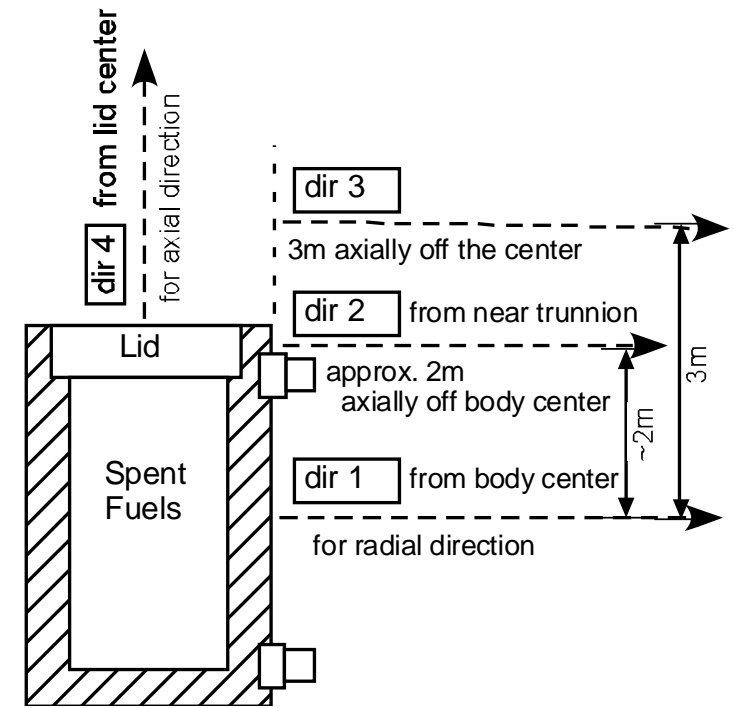

Figure 1. Directions of a SF cask for dose rate evaluation.

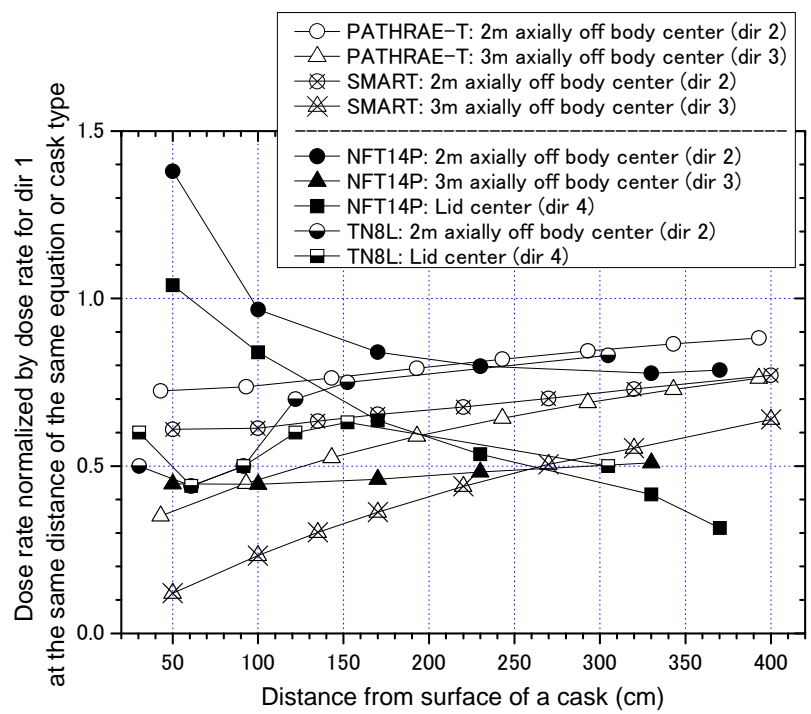

Figure 2. Attenuation curves normalized by a curve from the body center (dir 1 ) of the same equation or cask type.

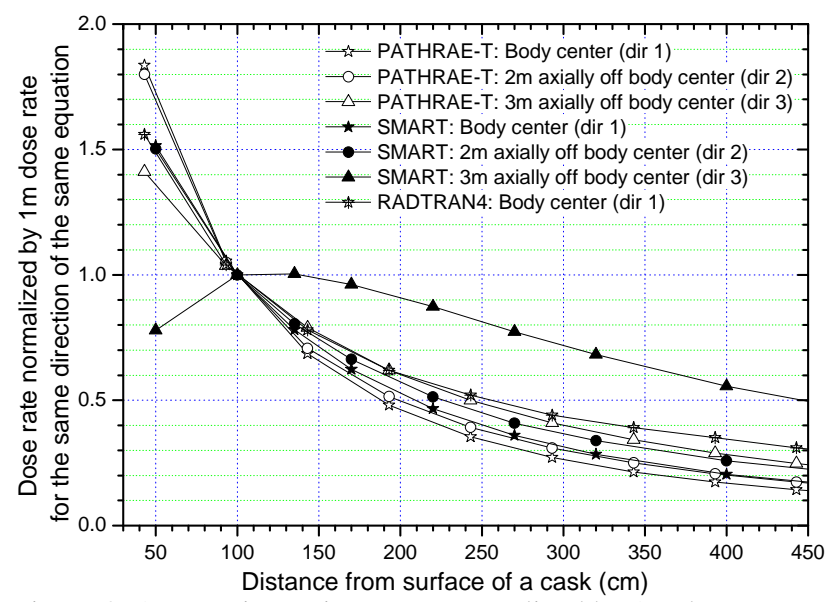

Figure 3. Attenuation ratio curves normalized by $1 \mathrm{~m}$ dose rate for the same direction by the equation. 


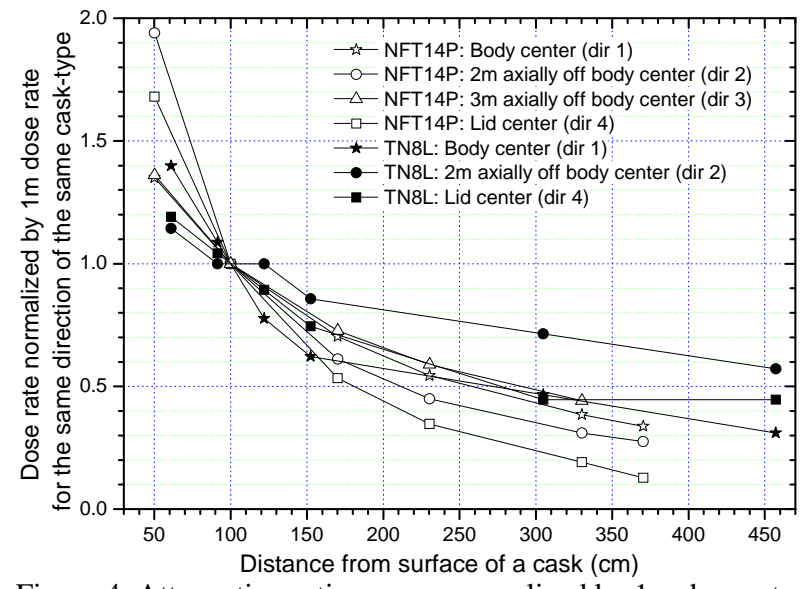

Figure 4. Attenuation ratio curves normalized by $1 \mathrm{~m}$ dose rate for the same direction by the cask type.

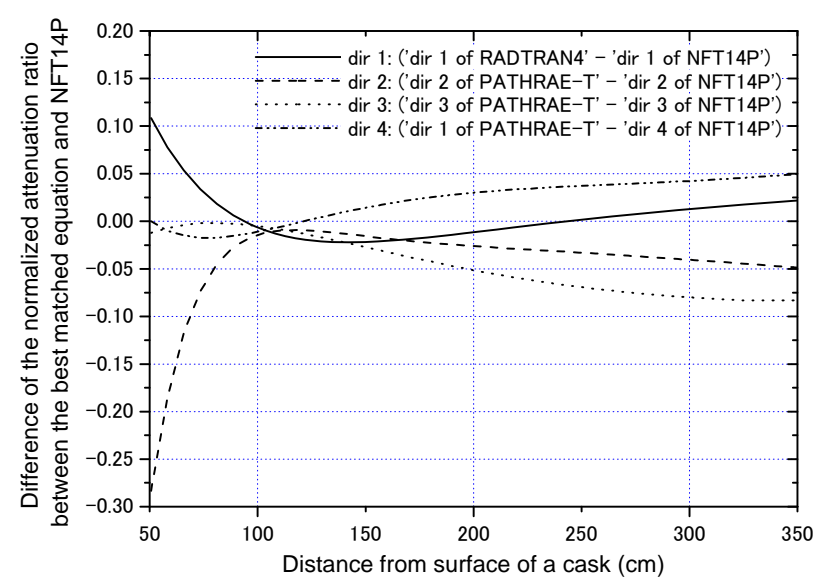

Figure 5. Relative differences of the normalized attenuation ratio curves between the best fit equation and the NFT14P.

The curves for the NFT14P are recalculated under the past Monte Carlo simulation [6]. The TN8L is a typical dry-type SF truck cask employed in land transport for which the measured dose rates are given in the U.S. report [7]. Both the PATHRAE-T and the RADTRAN4 have originally been verified just for a dry-type cask. As may be seen in Figure 2, in fact, a slope of the curve for dir 2 of the TN8L matches that of the PATHRAE-T. On the other hand, the curves near surface of the wet-type NFT14P widely vary depending on the direction and in particular the curves for dir 2 and 4 of the NFT14P are obviously distinguished by a high rise within $1 \mathrm{~m}$ as compared with those of the TN8L. It is therefore convenient to use $1 \mathrm{~m}$ as a reference distance for fitting in this case. It is also favorable that $1 \mathrm{~m}$ dose rates for dir 2 and 4 come close to that for dir 1 .

\subsection{Determination of fitting parameters for the NFT14P}

Fitting parameters for the NFT14P are determined as follows. $1 \mathrm{~m}$ dose rate for dir 1 must be separately given by measurement. $1 \mathrm{~m}$ dose rates for other directions can be evaluated using it. As shown in Figure 2, 1m dose rates for dir 2, 3 and 4 become almost 100, 45 and 85 percent respectively, compared to that for dir 1 . It is also found that $1 \mathrm{~m}$ dose rate for dir 3 is nearly the same as that calculated by the PATHRAE-T as shown in Figure 2. It may thus be possible that the PATHRAE-T can be used to determine $1 \mathrm{~m}$ dose rate for a direction within at least $3 \mathrm{~m}$ axially off the body.

As explained earlier, the normalized attenuation curves for dir 2 and 4 of the NFT14P are rising near surface of cask. Such a tendency cannot be expressed by any of the equations as shown in Figure 2, mainly because they assume that the dose rates are uniform on every surface of the body. As for the NFT14P, we find it difficult to choose one simple equation that can simulate every direction in an integrated manner. Instead we decide to apply an attenuation ratio to $1 \mathrm{~m}$ dose rate for each direction. The best fit ratio curve is chosen among those of the equations shown in Figure 3 by comparing them with those of the NFT14P shown in Figure 4.

Figure 5 shows differences in the normalized ratio curves between the NFT14P and the best fit equation for each direction. Within the distance from 50 to $350 \mathrm{~cm}$, it is found that the RADTRAN4 can be fit for dir 1 of the NFT14P, dir 2 of the PATHRAE-T can be fit for dir 2, dir 3 of the PATHRAE-T can be fit for dir 3, and dir 1 of the PATHRAE-T can be fit for dir 4. The ratio difference is not exceeding 0.10 all over the distance for dir 1, 3 and 4 of the NFT14P while it increases up to around 0.30 near the distance of $50 \mathrm{~cm}$ for dir 2 . It is indicated that there is still a limit on this fitting of the ratio curve for a high rise of dose near cask trunnion.

Table 1 summarizes the results of parameter determination. By using them, the dose rate map around the NFT14P can be evaluated with accuracy to some extent.

Table 1. Fitting parameters for simply calculating the dose rate map around the NFT14P.

\begin{tabular}{|c|l|l|}
\hline $\begin{array}{c}\text { Direction of } \\
\text { the NFT14P }\end{array}$ & $\begin{array}{c}\text { 1m dose rate } \\
\text { (ref. distance:1m) }\end{array}$ & $\begin{array}{c}\text { Best attenuation ratio to } \\
\text { the 1m dose rate }\end{array}$ \\
\hline 1 & $\begin{array}{l}\text { Given by separate } \\
\text { measurement }\end{array}$ & Dir 1 of the RADTRAN4 \\
\hline 2 & $\begin{array}{l}\text { Equal to 1m dose rate } \\
\text { for dir 1 }\end{array}$ & Dir 2 of the PATHRAE-T \\
\hline $\begin{array}{c}3 \text { or other } \\
\text { directions } \\
\text { axially off } \\
\text { the body }\end{array}$ & $\begin{array}{l}\text { Multiply 1m dose rate } \\
\text { for dir 1 by an } \\
\text { attenuation ratio at 1m } \\
\text { for the same direction } \\
\text { of the PATHRAE-T }\end{array}$ & $\begin{array}{l}\text { Dir 3 of the PATHRAE-T } \\
\text { (as for dir 3, with a ratio } \\
\text { difference up to 0.30 near } \\
\text { a distance of 50cm) }\end{array}$ \\
\hline 4 & $\begin{array}{l}\text { 85\% of 1m dose rate } \\
\text { for dir 1 }\end{array}$ & Dir 1 of the PATHRAE-T \\
\hline
\end{tabular}

\section{Evaluation of worker dose under cargo working environment in Japan}

\subsection{Cargo working parameters in Japan}

Figure 6 illustrates a typical configuration by a type of worker when a type-B cask is loaded at a harbor in Japan. There are three types of workers; handler, inspector and spotter. Table 2 shows an example of cargo working parameters per cask loading for each type 
of worker. These are conservatively measured by observation of actual work.

A handler carries out linking a paddle of hoisting attachment with cask trunnion in ship-hold (handler 1), and positioning a cask and bolting for tie-down onto a carrier of truck (handler 2). Four handler 2s are placed on the four corners on the carrier. An inspector surveys the dose rates around a cask both in ship-hold (inspector 1) and on a carrier of truck (inspector 2). A group of three inspectors measures the neutron and gamma dose rates both on surface and at $1 \mathrm{~m}$ distant from surface. The dose rates $2 \mathrm{~m}$ distant from truck are also measured by inspector 2.

In a ship-hold, just the dose rates on surface of cask are measured due to its narrowness. A spotter watches a cask handling on a ship-deck (spotter 1 ), a bolting near a truck (spotter 2). However exposure of spotter 1 is omitted because dose contributions of other casks in a ship-hold and a moving cask are not taken into account

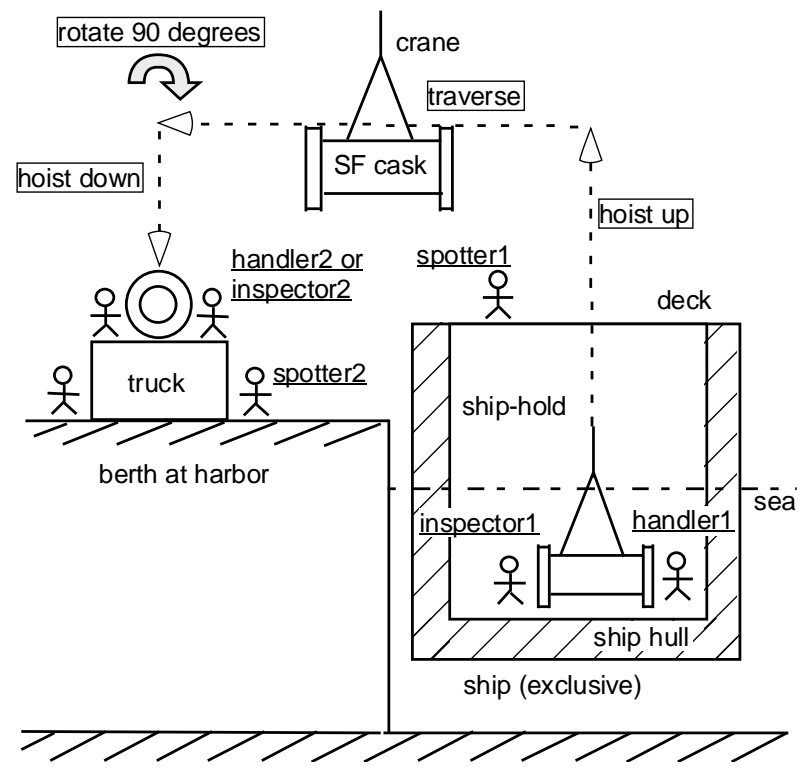

Figure 6. Worker type and configuration of cask loading in Japan. in this study.

\subsection{Evaluation results of cumulative and collective dose for cargo workers}

$1 \mathrm{~m}$ dose rate for dir1 of the NFT14P is supposed to be $4.5 \mu \mathrm{Sv} / \mathrm{h}$ at most according to track records [8]. Table 3 shows evaluation results of two indices that represent the radiological risk for a worker. Individual cumulative dose is calculated using the fitting parameters shown in Table 1, and the working parameters shown in Table 2. The collective dose is calculated by multiplying the individual dose by the number of workers. Note that they are the doses received for each loading/unloading of a cask.

Table 3. Evaluation results of the cumulative and collective dose for cargo workers per cask loading.

\begin{tabular}{|c|c|c|}
\hline type & $\begin{array}{c}\text { individual cumulative } \\
\text { dose }(\mu S v)\end{array}$ & $\begin{array}{c}\text { collective dose } \\
(\mathrm{man}-\mu \mathrm{Sv})\end{array}$ \\
\hline handler 1 & 0.27 & 1.08 \\
\hline handler 2 & 1.11 & 4.46 \\
\hline inspector 1 & 0.99 & 2.96 \\
\hline inspector 2 & 1.70 & 5.10 \\
\hline spotter 1 & \multicolumn{2}{|c|}{ (omitted) } \\
\hline \multirow{2}{*}{ spotter 2} & 0.82 & \multirow{2}{*}{3.51} \\
\hline & 0.02 & \\
\hline total & - & 17.1 \\
\hline
\end{tabular}

\subsection{Discussion in terms of radiological risk}

The highest personal dose is evaluated to $1.70 \mu \mathrm{Sv}$ per loading for an inspector 2. Even if an annual dose limit is as low as $1 \mathrm{mSv}$ for public, the annual number of SF cask loadings required to exceed the limit shall be over 580. In Japan, however, the actual number of loadings has been less than 100 at a port of a reprocessing plant and will not exceed double for years to come. It is even unlikely that the same worker has engaged in every inspection during a full-year. Consequently, the annual dose to the most exposed individual is estimated far less than the limit.

Table 2. Example of cargo working parameters per cask loading in Japan.

\begin{tabular}{|c|c|c|c|c|c|c|}
\hline type & $\begin{array}{l}\text { placement } \\
\text { position }\end{array}$ & $\begin{array}{c}\text { number of } \\
\text { workers }\end{array}$ & $\begin{array}{c}\text { dir \# } \\
\text { from cask }\end{array}$ & $\begin{array}{c}\text { distance from } \\
\text { cask surface (m) }\end{array}$ & $\begin{array}{c}\text { duration of } \\
\text { exposure (min) }\end{array}$ & exposure situation \\
\hline handler 1 & ship in hold & 4 & 2 & 0.5 & 2 & setting hoist attachment \\
\hline \multirow{2}{*}{ handler 2} & \multirow{2}{*}{$\begin{array}{l}\text { truck on } \\
\text { carrier }\end{array}$} & \multirow{2}{*}{4} & 2 & 0.5 & 6 & positioning, unlashing \\
\hline & & & 2 & 1 & 4 & bolting \\
\hline \multirow{2}{*}{ inspector 1} & \multirow{2}{*}{ ship in hold } & \multirow{2}{*}{3} & 2 & 0.5 & 7 & measuring surface dose rate \\
\hline & & & 4 & 0.5 & 3.5 & measuring surface dose rate \\
\hline \multirow{6}{*}{ inspector 2} & \multirow{6}{*}{$\begin{array}{l}\text { truck on } \\
\text { carrier }\end{array}$} & \multirow{6}{*}{3} & \multirow{3}{*}{2} & 0.5 & 7 & measuring surface dose rate \\
\hline & & & & 1 & 7 & measuring $1 \mathrm{~m}$ dose rate (cask) \\
\hline & & & & 3 & 7 & measuring $2 \mathrm{~m}$ dose rate (truck) \\
\hline & & & \multirow{3}{*}{4} & 0.5 & 3.5 & measuring surface dose rate \\
\hline & & & & 1 & 3.5 & measuring $1 \mathrm{~m}$ dose rate (cask) \\
\hline & & & & 3 & 3 & measuring $2 \mathrm{~m}$ dose rate (truck) \\
\hline spotter 1 & ship on deck & 2 & - & - & - & (on ship-deck, omitted) \\
\hline \multirow{3}{*}{ spotter 2} & \multirow{3}{*}{ around truck } & \multirow[b]{2}{*}{4} & 1 & 2 & 10 & bolting \\
\hline & & & 2 & 2 & 10 & bolting \\
\hline & & 1 & 1 & 2 & 5 & Inspection \\
\hline
\end{tabular}


A collective dose per loading is amounted to about 17 man- $\mu S v$ in a total of 19 workers. The worker's average dose is calculated to $0.9 \mu \mathrm{Sv}$. Compared with estimated exposures in U.S.[1], the dose values of this case are lower for cask loading but still higher for escort and off-link population along a road route. The occurrence of late effects can be negligible but we suggest that the working procedure and environment might be reviewed according to the ALARA principle.

\section{Conclusion}

Simple equations used for calculating dose rate map around a SF cask has been surveyed to determine the best fitting parameters for the Japanese wet-type SF cask, NFT14P. Then, the worker dose is practically evaluated using them under a typical environment of SF cask loading in Japan. As a result, it is estimated that the highest individual dose will be $1.7 \mu \mathrm{Sv}$ per loading for an inspector on a carrier of truck. However the annual dose is estimated far less than the public limit of $1 \mathrm{mSv}$ even if the same person has engaged a full-year inspection at a port in Japan. The collective dose per loading is amounted to about 17 man- $\mu S v$ in a total of 19 workers. The occurrence of late effects can be negligible but surely it is relatively higher than other situations of routine SF transportation.

This simple method enables to instantly evaluate the radiological risk with accuracy even if a cask-type as well as working environment is changed. However, fitting parameters for other cask-types must be prepared in a similar way. Further study will include investigation of the parameter characteristics by the cask-type and verification.

\section{Acknowledgements}

The author wishes to thank Dr. Kohtaro Ueki
(RADONet, Japan) for his helpful comments on the Monte Carlo calculation of dose rates around the NFT14P cask.

\section{References}

[1] K. S. Neuhauser and R. F. Weiner, Intermodal transfer of spent fuel, Proc. PATRAM'92, (1992), pp.427-433.

[2] H. Yamakoshi, A simple expression for radiation dose rate distribution around a cylindrical shell source with a finite height, Nucl. Sci. Eng. 88, 110 (1984).

[3] H. Yamakoshi, Simple formula for expression of dose rate distribution around spent fuel cask, Jour. Nucl. Sci. Tech. 22, 697 (1985).

[4] R. F. Weiner, Conservatism of RADTRAN line-source model for estimating worker exposures, Proc. PATRAM'92, (1992), pp.792-798.

[5] G. M. Sandquist, V. C. Rogers, A. A. Sutherland and G. B. Merrell, Exposures and Health Effects from Spent Fuel Transportation, RAE-8339/12-1, Rogers and Associates Engineering Corporation, Salt Lake City, UT (1985).

[6] K. Ueki and K. Sasaki, Radiation shielding analysis of a spent fuel transport cask with an actual configuration model using the Monte Carlo method -comparison with the discrete ordinates Sn method, Proc. PATRAM 2004, Berlin Germany Sept 20-24 (2004).

[7] C. J. Hostick, J. C. Lavender and B. H. Wakeman, Time/Motion Observation and Dose Analysis of Reactor Loading, Transportation and Dry Unloading of an Overweight Truck Spent Fuel Shipment, PNL-7206, Pacific Northwest Laboratories (1992).

[8] ATOMICA Database, Radiation Monitoring in Carrying Radioactive Materials (09-04-06-07), http://www.rist.or.jp/atomica/ (2004). [in Japanese] 